\title{
A Comparative Study of Tuning of a PID Controller Using Simulated Annealing for a Pitch Attitude Control System
}

\author{
Ahmet Akbulut, Tuğrul Adıgüzel
}

\begin{abstract}
This paper presents an approach based on simulated annealing in order to tune a proportional-integralderivative (PID) controller for an attitude pitch control system. The PID controllers, thanks to their simplicity and efficiency, are widely used in industrial applications. Studies on designing these controllers have focused on new approaches such as simulated annealing in order to satisfy requirements for diversifying applications. The main objective is to minimize defined performance metrics for tuning the PID parameters. Simulations are done using MATLAB and Simulink. The obtained results are compared with the conventional tuning methods (Ziegler-Nichols, Chien-Hrones-Reswick, Approximate MIGO step response and Skogestad IMC). The results demonstrate that simulated annealing provides less overshoot than other methods and reduces the performance metrics.
\end{abstract}

Keywords - evolutionary algorithms, PID tuning, process control, simulated annealing

\section{Introduction}

A controller monitors and affects the states of a dynamical system. PID controller is one of the earliest developed control methods and its construction is simple. It is also suitable for many industrial applications. PID controller is the most widely used control method due to its simplicity and effectiveness [1, $2,3,4]$. If suitable controller parameters aren't used, a control system works poorly and may even be unstable. Therefore, in order to achieve good control performance the controller parameters required to be set appropriately. In order to ensure the best possible control of a plant, setting the proportional, integral and derivative values of a controller is called the tuning of a pid controller [5, 6, 7]. However, the constantly evolving industry increases the complexity and reduces the performance of the traditional tuning algorithms. This was the reason that the researchers have directed their attention to the optimization techniques [8]. Among them evolutionary computation is widely studied optimization topic.

\section{Ahmet Akbulut}

Ankara University, Electrical and Electronics Engineering Department Turkey

Tuğrul Adıgüzel

TUBITAK SAGE

Turkey
Their simplicity and competitiveness brings them into a good choice among other techniques. Evolutionary computation algorithms are powerful optimization techniques that work on a set of potential solutions and find the optimal solution by means of competition among the potential solutions. In this paper a simulated annaeling-based tuning approach is used to tune a PID controller for simplified pitch attitude control system. Simulated annealing is a kind of stochastic search method to determine the optimal solution. It is a method frequently used in combinatorial optimization problems. It is inspired by the physical process of heating up a metal until it melts and then slowly cooling it down suffiently until it crystallizes in the form of a perfect lattice. The results obtained are compared with the other conventional techniques, namely Ziegler-Nichols, Chien-Hrones-Reswick, Approximate MIGO step response and Skogestad IMC in terms of transient systems characteristics and the selected performance metrics. As Performans metrics Integral of the Absolute Error (IAE), Integral of the Squared Error (ISE) and Integral Times Squared Error (ITSE) has been used. This paper is organized as follows: Section II presents the explanation of the Simulated Annealing algorithm and its implementation. Section III describes the design of a PID controller to optimize a simplified pitch attitude control system. The comparative studies and results are given in Section IV. Section V contains the conclusions based on the results.

\section{Simulated Annealing}

Simulated annealing is an optimization technique based on thermodynamic principles and it is a general method for the approximate solution of difficult combinatorial optimization problems. It was originally proposed by Kirkpatrick et al. [9] and Cerny [10]. It imitates the cooling process of molten metals through annealing. End of the process, atoms eventually form crystals having the lowest possible energy. However, the cooling rate determines the quality of crystal growth. If the molten metal is cooled quickly it does not reach a minimum energy state but instead the system may end up in a polycrystalline state. This higher energy state might equal to a sub-optimal solution. Cooling process is simulated by controlling a temperature-like parameter based on the Boltzmann probability distribution. The algorithm normally begins with a random initial solution. Simulated annealing finds a neighborhood solution by means of a random function. If the neighborhood solution is worse, the algorithm accepts that solution with a given probability. The neighborhood is defined as the group of solutions that can be reached from the current solution using one move only. The algorithm is terminated when a predefined stopping criterion is reached. 
Proc. of the Intl. Conf. on Advances in Computing, Control and Networking - ACCN 2015.

Copyright (C) Institute of Research Engineers and Doctors, USA .All rights reserved.

ISBN: 978-1-63248-038-5 doi: 10.15224/ 978-1-63248-038-5-13

Given a sequence of moves, the system is assumed to change its state from energy $E_{\text {old }}$ to energy $E_{\text {new }}$ with probability

$$
\mathrm{P}(\mathrm{E})=\exp (-(\text { Enew-Eold }) / \mathrm{kT})
$$

where $\mathrm{k}$ is the Boltzmann constant. If $\mathrm{E}_{\text {new }}<\mathrm{E}_{\text {old }}$ the system always accepts this move. If $\mathrm{E}_{\text {new }}>\mathrm{E}_{\text {old }}$ then this new configuration can be accepted with probability $\operatorname{Pr}(0<\operatorname{Pr}<1)$ and therefore, this enables the system to escape a local minimum. When the temperature is very low, non-improving solutions will almost never be accepted because of low acceptance probability. The simulated annealing algorithm may be expressed as pseudocode:

\section{Initialise Temperature (T)}

Generate random configuration Xold which has cost $E_{\text {old }}$

Xbest $\leftarrow$ Xold

Ebest $\leftarrow$ Eold

WHILE T > Tmin DO

FOR $i=1$ to numloop DO

generate, Xnew, from neighborhood function

calculate new cost, Enew

$\Delta E \leftarrow$ Enew - Eold

generate random such that random $\epsilon[0,1)$

IF $\Delta E<0$ or random $<$ prob $=\exp (-\Delta E / T)$

THEN

Xold $\leftarrow$ Xnew

Eold $\leftarrow$ Enew

IF Enew < Ebest

THEN

Xbest $\leftarrow$ Xnew

Ebest $\leftarrow$ Ebest

END IF

END IF

END FOR

$T:=\alpha T,(0<\alpha<1)$

END WHILE

RETURN Ebest, Xbest

In this study, initializing the values of theparameters is as follows:
Initial temperature: 1000,

Number of iterations: 100 ,

$\alpha: 0.9$

\section{PID Controller For A Pitch Attitude System}

PID parameters consist of three terms: proportionality $(\mathrm{Kp})$, integral $(\mathrm{Ki})$ and derivative $(\mathrm{Kd})$. Proper setting of these parameters improves the dinamic response of a system, reduces overshoot, removes steady-state error and increases stability. The transfer function of a PID controller is as follows:

$$
\mathrm{C}(\mathrm{s})=\mathrm{Kp}+\mathrm{Ki} / \mathrm{s}+\mathrm{Kds}
$$

In this work, a simplified pitch attitude outopilot control system from [11] is selected as plant.

The structure of the control system is shown in Fig.1.

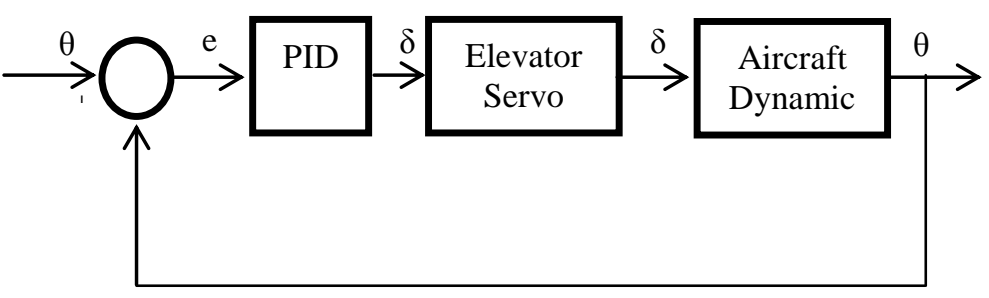

Figure 1. PID control structure for a pitch attitude conrol system.

Transfer function of the elevator servo and aircraft dynamics are:

$$
\begin{aligned}
& \frac{\delta_{e}}{\delta_{\text {ก }}}=\frac{A}{\tau s+1} \\
& \frac{\theta}{\delta_{\theta}}=\frac{-3}{s^{2}+2 s+5}
\end{aligned}
$$

PID parameters $(\mathrm{Kp}, \mathrm{Ki}, \mathrm{Kd})$ are tuned by using ZieglerNichols, Chien-Hrones-Reswick, Approximate MIGO step response and Skogestad IMC algorithms for the system [12]. Step response of the system for PID controller tuned through these algoritms can be seen in Fig. 2. - Fig. 5. 
Proc. of the Intl. Conf. on Advances in Computing, Control and Networking - ACCN 2015.

Copyright $\odot$ Institute of Research Engineers and Doctors, USA .All rights reserved.

ISBN: 978-1-63248-038-5 doi: 10.15224/ 978-1-63248-038-5-13

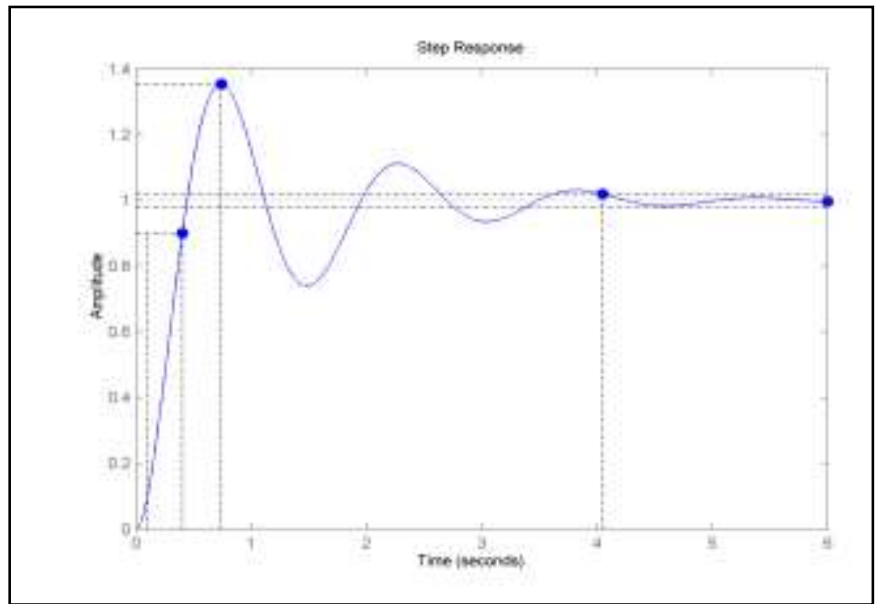

Figure 2. System step response for PID controller tuned by Ziegler-Nichols algorithm. (Rise time: 0.303 s, overshoot: \%35.5, settling time: 4.05 s) PID control structure for a pitch attitude conrol system.

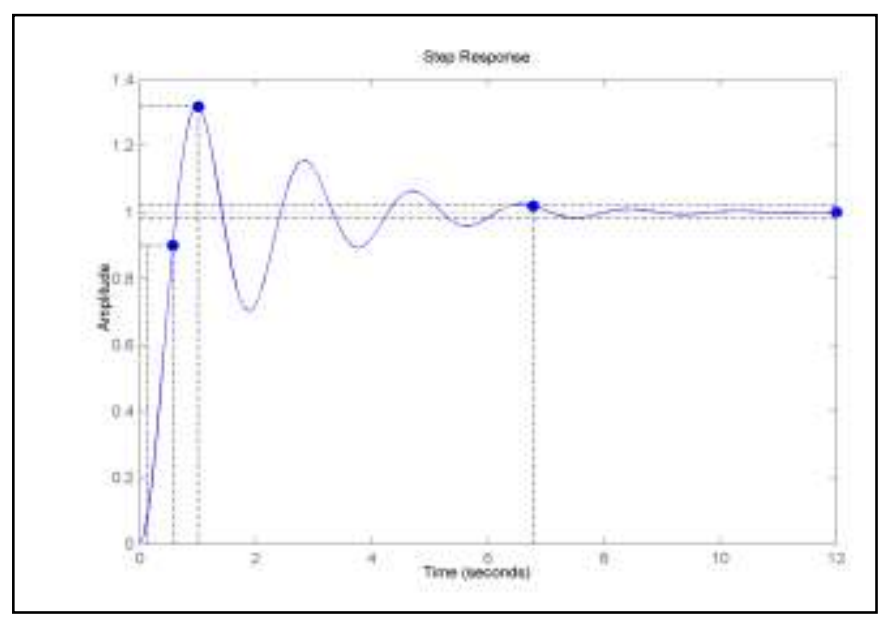

Figure 3. System step response for PID controller tuned by Chien-HronesReswick algorithm. (Rise time: 0.425 s, overshoot: \%31.9, settling time: 6.78 s)

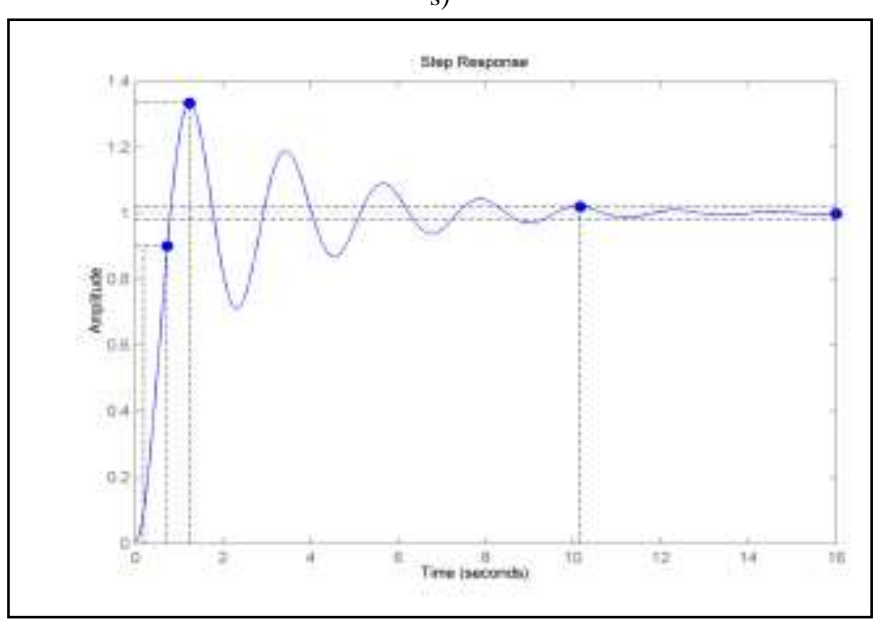

Figure 4. System step response for PID controller tuned by Approximate MIGO step response algorithm. (Rise time: $0.539 \mathrm{~s}$, overshoot: \%33.3, settling time: $10.02 \mathrm{~s})$

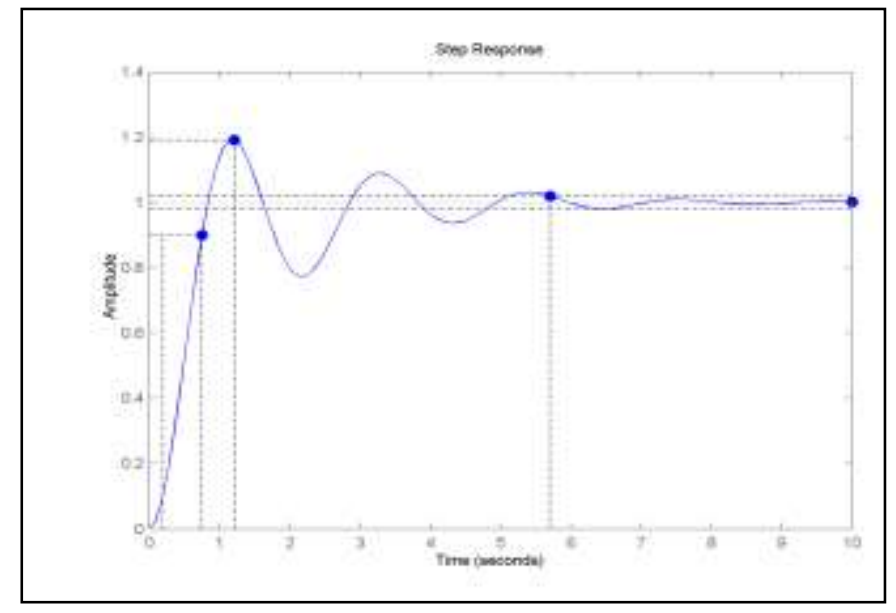

Figure 5. System step response for PID controller tuned by Skogestad IMC algorithm. (Rise time: 0.559 s, overshoot: \%19.1, settling time: $5.71 \mathrm{~s}$ )

PID parameters belong to the all methods and the obtained results are listed in Table 1.

TABLE I. PID PARAMETERS AND TUNING RESULTS

\begin{tabular}{|l|l|l|l|l|}
\hline \multirow{2}{*}{} & \multicolumn{4}{|c|}{ Algorithm } \\
\cline { 2 - 5 } & $\begin{array}{l}\text { Ziegler- } \\
\text { Nichols }\end{array}$ & $\begin{array}{l}\text { Chien- } \\
\text { Hrosen- } \\
\text { Reswick }\end{array}$ & $\begin{array}{l}\text { Approximate } \\
\text { MIGO S.R. }\end{array}$ & $\begin{array}{l}\text { Skogestad } \\
\text { IMC }\end{array}$ \\
\hline $\mathrm{K}_{\mathrm{p}}$ & 49.3384 & 29.4667 & 17.2880 & 19.8482 \\
\hline $\mathrm{K}_{\mathrm{i}}$ & 79.578 & 47.527 & 41.162 & 31.505 \\
\hline $\mathrm{K}_{\mathrm{d}}$ & 7.6474 & 3.1938 & 1.9922 & 2.0484 \\
\hline Rise time (s) & 0.303 & 0.425 & 0.539 & 0.559 \\
\hline Peak amplitude & 1.35 & 1.32 & 1.33 & 1.19 \\
\hline \multirow{2}{*}{ Overshoot (\%) } & 35.5 & 31.9 & 33.3 & 1.21 \\
\cline { 2 - 5 } & & 1 & 1.24 & 5.11 \\
\cline { 2 - 5 } & 0.741 & 1.02 & 10.2 & 1 \\
\hline Sinal value & 1 & 6.78 & & \\
\hline
\end{tabular}


Proc. of the Intl. Conf. on Advances in Computing, Control and Networking - ACCN 2015.

Copyright $(\odot$ Institute of Research Engineers and Doctors, USA .All rights reserved.

ISBN: 978-1-63248-038-5 doi: 10.15224/ 978-1-63248-038-5-13

\section{Iv. Simulated Annealing Simulations And Results}

The simulations are realized by MATLAB and Simulink. Simulink model used to tune PID parameters is shown in Fig. 6.

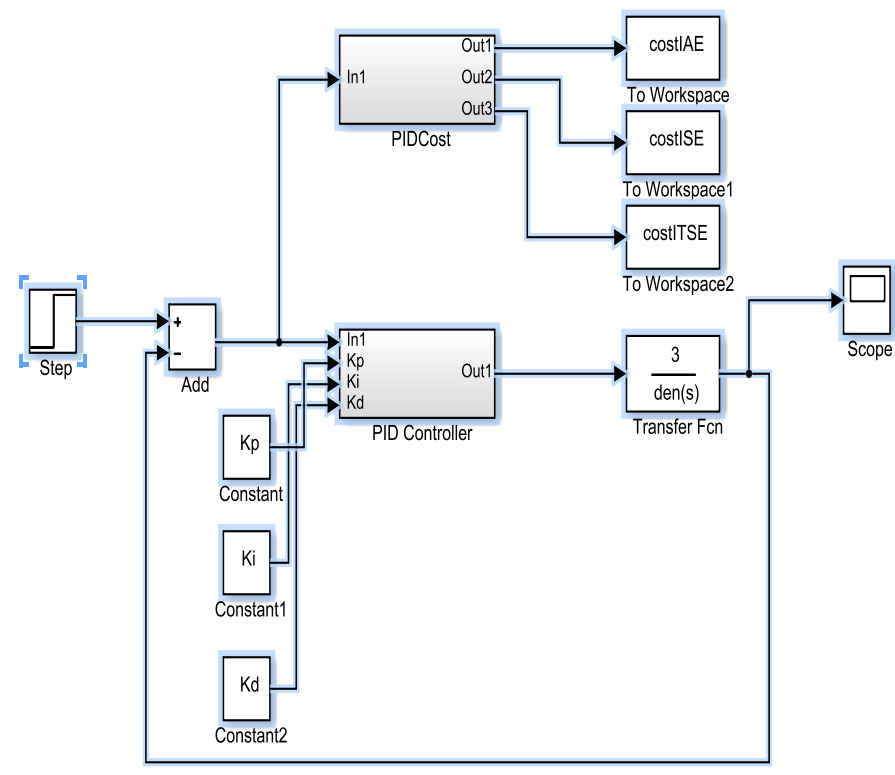

Figure 6. Simulink model for simulated annealing tuning method.

Termination of simulated annealing algorithm can take place either when the maximum number of iterations attained or with the obtainment of adequate objective function value. In this paper the termination criteria is taken account of maximum number of iterations. The Simulated Annealing is implemented with the Integral of the Absolute Error (IAE), Integral of the Squared Error (ISE) and Integral Times Squared Error (ITSE) performance criterions for 100 iterations. These performance criterions are given by:

$$
\begin{aligned}
\text { IAEE } & =\int_{0}^{T}|e(t)| d t \\
I S E & =\int_{0}^{T} e(t)^{2} d t \\
I T S E & =\int_{0}^{T} t e(t)^{2} d t
\end{aligned}
$$

The PID parameters $\left(\mathrm{K}_{\mathrm{p}}, \mathrm{K}_{\mathrm{i}}, \mathrm{K}_{\mathrm{d}}\right)$, found by using simulated annealing algorithm with IAE, ISE, and ITSE performance metrics, are shown in Table 2.
TABLE II. THE PID PARAMETERS OBTAINED BY SIMULATED ANNEALING METHOD

\begin{tabular}{|l|l|l|l|}
\hline & \multicolumn{3}{|c|}{ Metric } \\
\hline Parameter & \multicolumn{1}{|c|}{$\boldsymbol{I A E}$} & \multicolumn{1}{|c|}{$\boldsymbol{I S E}$} \\
\hline $\mathrm{K}_{\mathrm{p}}$ & 51.6164 & 36.4343 & 30.0551 \\
\hline $\mathrm{K}_{\mathrm{i}}$ & 82.7764 & 60.5109 & 60.4038 \\
\hline $\mathrm{K}_{\mathrm{d}}$ & 9.8806 & 9.8981 & 5.5091 \\
\hline Rise time (s) & 0.29 & 0.356 & 0.407 \\
\hline $\begin{array}{l}\text { Peak amplitude } \\
\text { Overshoot (\%) } \\
\text { At time (s) }\end{array}$ & 1.3 & 1.14 & 1.29 \\
\cline { 2 - 4 } & 29.7 & 13.6 & 28.7 \\
\cline { 2 - 4 } & 0.692 & 0.767 & 0.949 \\
\hline Settling time (s) & 3.18 & 2.16 & 5.01 \\
\hline
\end{tabular}

Finally comparative results are shown in Table 3.

TABLE III. COMPARISON PERFORMANCE OF SIMULATED ANNEALING AND THE OTHER TECHNIQUES

\begin{tabular}{|l|l|l|l|l|l|}
\hline & \multicolumn{5}{|c|}{ Algorithm } \\
\cline { 2 - 6 } & $\begin{array}{l}\text { Ziegler- } \\
\text { Nichols }\end{array}$ & $\begin{array}{l}\text { Chien- } \\
\text { Hrosen- } \\
\text { Reswick }\end{array}$ & $\begin{array}{l}\text { Approximate } \\
\text { MIGO S.R. }\end{array}$ & $\begin{array}{l}\text { Skogestad } \\
\text { IMC }\end{array}$ & $\begin{array}{l}\text { Simulated } \\
\text { Annealing }\end{array}$ \\
\hline IAE & 0.8252 & 1.1558 & 1.5276 & 1.0282 & 0.6534 \\
\hline ISE & 0.4032 & 0.5059 & 0.6388 & 0.5002 & 0.2074 \\
\hline ITSE & 0.1807 & 0.3424 & 0.5975 & 0.2540 & 0.1342 \\
\hline
\end{tabular}

All the tuning methods give different responses. Simulated annealing optimized by using IAE metric gives the best values of rise time followed by Ziegler-Nichols tuning method. However, in terms of overshoot, only the Skogestad IMC method gives the better performance than simulated annealing optimized by all the experimented metrics. In terms of settling time, simulated annealing method gives the best performance over all the other methods.

\section{v. Conclusions}

In tih study, PID controllers for a pitch attitute control system are tuned by using Ziegler-Nichols method, ChienHrones-Reswick method, Approximate MIGO step response method, Skogestad IMC method and simulated annealing algorithm. As performance metrics (objective functions) Integral of the Absolute Error (IAE), Integral of the Squared Error (ISE) and Integral Times Squared Error (ITSE) have been used. Simulated annealing has showed the best performance in terms of rise time. For a desing perspective delaling with overshoot, simulated annealing has also showed better performanec except Skogestad IMC method. At it again, simulated annealing showed the best performance in terms of settling time. Consequently, the simulated annealing optimization method can be considered as a substantial alternative for tuning problem of the PID parameters. 


\section{References}

[1] H. Bervani, T. Hiyama, "Multiobjective PI/PID control design using an iterative linear matrix inequalities algorithm", Int. J. Control Autom. Syst. 5 (2) (2007) pp. 117-127.

[2] A. Chipperfield, P. Fleming, "Multiobjective gas turbine engine controller design using genetic algorithm", IEEE Trans. Ind. Electron. 43 (5) (1996) pp.583-587, doi:10.1109/41.538616.

[3] W.D. Chang, S.-P. Shih, "PID controller design of nonlinear systems using an improved particle swarm optimization approach", Commun. Nonlinear Sci.Numer. Simul. 15 (11) (2010), pp. 3632-3639.

[4] A. Herreros, E. Baeyens, J. Peran, "Design of PID-type controllers using multiobjective genetic algorithms", ISA Trans. 41 (2002), pp.457-472, doi:10.1016/S0019-0578(07)60102-5.

[5] M.H. Hung, A.-S. Shu, S.-J. Ho, S.-F. Hwang, S.-Y. Ho, "A novel intelligent multiobjective simulated annealing algorithm for designing robust PID controllers", IEEE Trans. Syst. Man Cybern. A Syst. Humans 38 (2) (2008), pp.319-330, doi:10.1109/TSMCA.2007.914793.

[6] C.S. Tseng, B.-S. Chen, "Multiobjective PID control design in uncertain robotic systems using neural network elimination scheme," IEEE Trans. Syst. Man Cybern. A Syst. Humans 31 (6) (2001), pp.632-644, doi:10.1109/3468.983419

[7] R.H.C. Takahashi, P.-L.D. Peres, P.-A.V. Ferreira, "Multiobjective H2/H1 guaranteed cost PID design”, IEEE Control Syst. Mag. 17 (5) (1997), pp. 37-47, doi:10.1109/37.621468.

[8] K.H. Ang, G. Chang, Y. Li, "PID control system analysis, design and technology", IEEE Trans. Control Syst. Technol. 13 (4) (2005), pp. 559577, doi:10.1109/TCST.2005.847331.

[9] S. Kirkpatrick, C. D. Gelatt, M. P. Vecchi, "Optimization by Simulated Annealing", Science 13 May 1983: Vol. 220 no. 4598 pp. 671-680 DOI: 10.1126/science.220.4598.671.

[10] V. Cerny, "Thermodynamical Approach to the Traveling Salesman Problem: An Efficient Simulation Algorithm", J. Opt. Theory Appl., 45(1), pp.41-51, 1985.

[11] N. Robert, Flight Stability and Automatic Control 2nd Ed 1997, McGRAW-HILL International Edition.

[12] J. Karl Astrom, H. Tore, Advanced PID Control, ISA - Instrumentation, Systems, and Automation Society ISBN-10: 1556179421, 15 Jun 2006.

About Author (s):

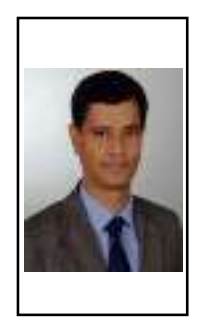

Ahmet AKBULUT was born in Afsin. He received his B.S. degree in Electronics Engineering from the Ankara University in 1998. He received his M.S. and Ph.D. degrees in Electronics Engineering from the same university in 2000 and 2006, respectively. He is an Assistant Professor

at the Electrical and Electronics

Engineering Department, Ankara University. His research interests include digital communication, optical communication and mobile robotics.

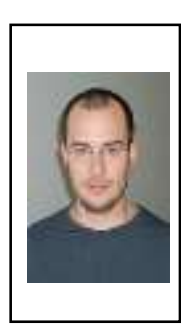

Tuğrul ADIGUZEL received his B.S. degree in Electronics Engineering from the Ankara University in 1999. He received his M.S. and Ph.D. degrees in Electronics Engineering from the same university in 2001 and 2008, respectively. His research interests include nonlinear control theory and robotics in general. 